\title{
Bitter melon (Momordica charantia $L$.) inhibits adipocyte hypertrophy and down regulates lipogenic gene expression in adipose tissue of diet-induced obese rats
}

\author{
Hui-Ling Huang ${ }^{1,2}$, Ya-Wen Hong ${ }^{1}$, You-Hong Wong ${ }^{3}$, Ying-Nien Chen ${ }^{4}$, Jong-Ho Chyuan ${ }^{5}$,
} Ching-Jang Huang ${ }^{6,7}$ and Pei-Min Chao ${ }^{1,3 *}$

${ }^{1}$ Institute of Nutrition, China Medical University, Taichung, Taiwan

${ }^{2}$ Department of Health and Nutrition, Chia Nan University of Pharmacy and Science, Tainan, Taiwan

${ }^{3}$ Department of Nutrition, China Medical University, Taichung, Taiwan

${ }^{4}$ Department of Medical Laboratory Science and Biotechnology, China Medical University, Taichung 404, Taiwan

${ }^{5}$ Hualien District Agricultural Research and Extension Station, Hualien, Taiwan

${ }^{6}$ Department of Biochemical Science and Technology, College of Life Science, National Taiwan University, Taipei, Taiwan

${ }^{7}$ Division of Nutritional Science, Institute of Microbiology and Biochemistry, College of Life Science, National Taiwan University, Taipei, Taiwan

(Received 23 February 2007 - Revised 15 May 2007 - Accepted 11 June 2007)

Bitter melon (Momordica charantia; BM) has been shown to ameliorate diet-induced obesity and insulin resistance. To examine the effect of BM supplementation on cell size and lipid metabolism in adipose tissues, three groups of rats were respectively fed a high-fat diet supplemented without (HF group) or with $5 \%$ lyophilised BM powder (HFB group), or with $0.01 \%$ thiazolidinedione (TZD) (HFT group). A group of rats fed a lowfat diet was also included as a normal control. Hyperinsulinaemia and glucose intolerance were observed in the HF group but not in HFT and HFB groups. Although the number of large adipocytes $(>180 \mu \mathrm{m})$ of both the HFB and HFT groups was significantly lower than that of the HF group, the adipose tissue mass, TAG content and glycerol-3-phosphate dehydrogenase activity of the HFB group were significantly lower than those of the HFT group, implying that BM might reduce lipogenesis in adipose tissue. Experiment 2 was then conducted to examine the expression of lipogenic genes in adipose tissues of rats fed low-fat, HF or HFB diets. The HFB group showed significantly lower mRNA levels of fatty acid synthase, acetyl-CoA carboxylase-1, lipoprotein lipase and adipocyte fatty acid-binding protein than the HF group $(P<0 \cdot 05)$. These results indicate BM can reduce insulin resistance as effective as the anti-diabetic drug TZD. Furthermore, BM can suppress the visceral fat accumulation and inhibit adipocyte hypertrophy, which may be associated with markedly down regulated expressions of lipogenic genes in the adipose.

Bitter melon: Peroxisome proliferator-activated receptor: Thiazolidinedione: Adipocyte hypertrophy: Lipogenic genes

The metabolic syndrome has become a major public health problem in the whole world. It is characterised by the clustering of risk factors, including insulin resistance, obesity or abdominal obesity, hypertension and dyslipidaemia in an individual which dramatically increases the risk of developing CVD and type 2 diabetes mellitus ${ }^{1}$. Momordica charantia, the fruit of which is known as karella, bitter gourd or bitter melon (BM), is a common edible vegetable in Asia. Physiological benefits, including hypoglycaemia, hypolipidaemia, anti-virus and anti-carcinogenic effects, have been reported, but the mechanisms and functional components remain to be elucidated $^{2,3}$.

Using a transactivation assay, we found that an ethyl acetate extract of BM activates both PPAR $\alpha$ and PPAR $\gamma^{4}$. PPAR are ligand-activated transcription factors belonging to the nuclear receptor superfamily. Three subtypes (PPAR $\alpha, \beta$ and $\gamma$ ) have been identified and shown to play a key role in the control of lipid and glucose homeostasis as transcription factors regulating genes encoding enzymes involved in these processes ${ }^{5}$. Fibrate-class hypolipidaemic drugs and thiazolidinedione (TZD)-class anti-diabetic drugs are, respectively, specific PPAR $\alpha$ and PPAR $\gamma$ ligands, but efforts are now being made to screen for and develop PPAR $\alpha$ and $\gamma$ dual agonists, focusing on the metabolic syndrome, to resolve the problems of insulin resistance, hyperlipidaemia and central obesity simultaneously ${ }^{6}$. PPAR activators of food or diet origin may provide health benefits without toxicity concerns, as long as the food or diet is consumed in a reasonable amount on a regular basis. With the reported PPAR $\alpha$ and PPAR $\gamma$ activation capability ${ }^{4}, \mathrm{BM}$ is therefore implicated in a potential dietary

Abbreviations: ACC-1, acetyl-CoA carboxylase-1; ADD1/SREBP-1c, adipocyte determination and differentiation factor 1/sterol regulatory element-binding protein1c; aP2, adipocyte fatty acid-binding protein; BM, bitter melon; DIO, diet-induced obesity; FAS, fatty acid synthase; G3PDH, glycerol-3-phosphate dehydrogenase; HF, high-fat, HFB, high-fat and bitter melon; HFT, high-fat and thiazolidinedione; LF, low-fat; LPL, lipoprotein lipase; TZD, thiazolidinedione.

* Corresponding author: Dr Pei-Min Chao, fax +886 42206 2891, email pmchao@mail.cmu.edu.tw 
intervention regimen for the prevention and amelioration of the metabolic syndrome.

BM has also been shown to reduce the accumulation of visceral fat in high-fat (HF) diet-fed rats, and it was suggested that the insulin-sensitising and glucose-lowering benefits of BM might be due to this anti-adiposity effect ${ }^{7}$. Circulating levels of catecholamine and NEFA, lipid oxidation in the liver and muscle and mitochondria uncoupling are reported to be all increased in BM-supplemented rats ${ }^{8,9}$. However, morphometric and metabolic changes in adipocytes have never been explored. Since it is believed that hypertrophic adipocytes reduce insulin sensitivity by releasing cytokines that interfere with insulin signalling ${ }^{10}$, the impact of $\mathrm{BM}$ on cell size and lipid metabolism in adipose tissues warrants evaluation. These effects were investigated in experiment 1 of the present study and compared with a selective PPAR $\gamma$ agonist, TZD, which ameliorates insulin resistance but is also well known for its adipogenic side effect ${ }^{11}$. As the results obtained in experiment 1 implied that lipogenesis in adipose tissues is decreased by BM supplementation, the gene expression of lipogenic enzymes was further examined in experiment 2.

\section{Materials and methods}

\section{Preparation of lyophilised bitter melon powder}

The wild BM ( $M$. charantia L.) used in the present study was provided by the Hualien District Agricultural Research and Extension Station, Agricultural Council, Executive Yuan, Taiwan. After washing and slicing, the whole fruit (including seeds) was freeze-dried and powdered. In a previous study, although the ethyl acetate extract from seed or flesh activated PPAR $\alpha$ in a transactivation assay, the extract from the whole fruit showed still higher activating potency than the seed and flesh ${ }^{4}$. Therefore, we chose the whole fruit to be used in the present study. Proximate analysis showed that the lyophilised BM powder contained $3.8 \%$ water, $38.2 \%$ dietary fibre, $6.7 \%$ minerals, $4.5 \%$ crude protein and $2.7 \%$ crude fat.

\section{Animals and diets}

Male Wistar rats (aged 6 weeks; purchased from the Animal Centre of the National Taiwan University) were housed individually in stainless-steel wire cages in a room maintained at $23 \pm 2{ }^{\circ} \mathrm{C}$ on a controlled $12 \mathrm{~h}$ light-dark cycle, with free access to feed and tap water. The feed intake was recorded every $2 \mathrm{~d}$ and the body-weight gain weekly. The protocols for animal care and handling were approved by the Institutional Animal Care and Use Committee of the China Medical University. Table 1 shows the compositions of the four test diets: a low-fat (LF) diet (5\% fat; AIN76) and three HF diets (unsupplemented HF diet, HF and BM (HFB) diet, and HF and TZD (HFT) diet; 30\% fat), following $\mathrm{Hsu} \& \mathrm{Huang}^{12}$. In the HFB diet, $5 \%(\mathrm{w} / \mathrm{w})$ $\mathrm{BM}$ powder was substituted into the HF diet for the equivalent amount of protein, fat, cellulose and minerals. In the HFT diet, TZD was added to the HF diet as $0.01 \%$ pioglitazone, kindly supplied by Takeda Pharmaceutical Company
Table 1. Composition of the test diets

\begin{tabular}{lrrrr}
\hline & LF & HF & HFB & HFT \\
\hline Casein $(\mathrm{g} / \mathrm{kg})$ & 200 & 260 & 258 & 260 \\
Maize starch (g/kg) & 325 & 160 & 136 & 160 \\
Sucrose $(\mathrm{g} / \mathrm{kg})$ & 325 & 160 & 160 & 160 \\
Soyabean oil $(\mathrm{g} / \mathrm{kg})$ & 50 & 10 & 10 & 10 \\
Butter (g/kg) & - & 290 & 289 & 290 \\
Cellulose (g/kg) & 50 & 61 & 42 & 61 \\
Mineral mixture $(\mathrm{g} / \mathrm{kg})^{*}$ & 35 & 42 & 39 & 42 \\
Vitamin mixture $(\mathrm{g} / \mathrm{kg})^{*}$ & 10 & 12 & 12 & 12 \\
DL-Methionine $(\mathrm{g} / \mathrm{kg})$ & 3 & 3 & 3 & 3 \\
Choline $(\mathrm{g} / \mathrm{kg})$ & 2 & 2 & 2 & 2 \\
Bitter melon powder $(\mathrm{g} / \mathrm{kg}) \dagger$ & - & - & 50 & - \\
Pioglitazone $(\mathrm{g} / \mathrm{kg})$ & - & - & - & $0 \cdot 1$ \\
Energy (MJ/kg) & 16 & 21 & 21 & 21 \\
\hline
\end{tabular}

LF, low-fat control diet; HF, high-fat control diet; HFB, high-fat diet containing $5 \%$ bitter melon (Momordica charantia) powder; HFT, high-fat diet containing $0.01 \%$ pioglitazone.

${ }^{*}$ AIN-76 mineral mixture and AIN-76 vitamin mixture.

tProximal analysis showed that the lyophilised bitter melon powder contained $3.8 \%$ water, $38.2 \%$ fibre, $6.7 \%$ ash, $4.5 \%$ protein and $7 \%$ fat.

Ltd (Osaka, Japan); this dose is equivalent to about $5 \mathrm{mg} / \mathrm{kg}$ body weight per $\mathrm{d}$.

\section{Experiment 1}

The aim of this experiment was to examine the anti-adiposity and insulin-sensitising effects of BM and compare them with those of TZD. Twenty-four rats were fed the $\mathrm{HF}$ diet for 3 weeks (weeks -3 to -1 ) to induce obesity (diet-induced obesity; DIO), and then separated into the HF, HFB and HFT groups (eight rats per group). As it was possible that the bitter taste of $\mathrm{BM}$ might cause a drop in feed intake, the HFB group underwent an adaptation period (week 0) in which they were given diet containing $1 \% \mathrm{BM}$, which was raised to $3 \%$ after $2-\mathrm{d}$, then to $5 \%$ after $3-\mathrm{d}$. During this period, the HF and HFT groups received the $\mathrm{HF}$ diet. After this period, the rats were formally separated into three groups and fed their individual diets for 9 weeks (weeks 1-9). In addition, an LF control group ( $n$ 8) received the LF diet for the whole study period (weeks -3 to 9 ). In experiment 1 , bio-indexes for insulin sensitivity and tissue mass, cell size, lipid metabolism and mRNA levels of mature adipocyte markers in adipose were measured.

\section{Experiment 2}

The aim of this experiment was to test if lipogenic gene expression was reduced in the adipose tissue of BM-treated rats. Rats were initially fed an LF ( $n$ 6) or HF diet (DIO; $n$ 12), then the DIO rats were divided into two groups of six to receive the HF or HFB diet for 9 weeks with the habituation process, exactly as described for experiment 1 . At the end, rats were killed in the fed state. The retroperitoneal, epididymal and inguinal fats were excised and weighed. The adipose tissue was stored at $-70^{\circ} \mathrm{C}$ for RNA isolation. The mRNA levels of lipogenic genes and their transcriptional regulator, PPAR $\gamma$ and adipocyte determination and differentiation factor $1 /$ sterol regulatory element-binding protein-1c (ADD1/SREBP-1c) were measured in retroperitoneal and epididymal fat. 


\section{Adipose cell size}

The method used to measure adipose cell size was a slight modification of that of Hirsch \& Gallian ${ }^{13}$. Briefly, fat slices $(<200 \mathrm{mg})$ cut from the epididymal and retroperitoneal fat were rinsed with saline at $37^{\circ} \mathrm{C}$, then fixed in $2 \%$ osmium tetroxide in collidine- $\mathrm{HCl}$ buffer $(\mathrm{pH} \mathrm{7.4)}$ at room temperature. After $3 \mathrm{~d}$, the fixation solution was removed and replaced by saline for $24 \mathrm{~h}$, then the saline was removed and $10 \mathrm{ml}$ of 8 M-urea added for $24 \mathrm{~h}$ with occasional swirling to liberate the cells. Finally, the adipocytes were isolated by successive filtering through nylon mesh screens with diameters of 235 and $10 \mu \mathrm{m}$ and washed with $0.01 \%$ Triton X-100 in distilled water. The numbers of adipocytes with different diameter ranges were counted using a Coulter counter (Coulter Corporation, Miami, FL, USA).

\section{Lipid content of adipose tissue}

For the analysis of adipose lipid content, total lipid was extracted from the epididymal and retroperitoneal fat using the Folch method ${ }^{14}$. The total lipid content of the adipose tissue samples was determined by weighing after complete removal of the organic solvent.

\section{Activities of lipid metabolism enzymes}

Glycerol-3-phosphate dehydrogenase (G3PDH), a key lipogenic enzyme in adipose tissue, was measured following Kozak \& Jensen ${ }^{15}$. Briefly, the adipose tissue was homogenised in 4 volumes of ice-cold $50 \mathrm{mM}$-tri(hydroxymethyl)-aminomethane (tris) buffer ( $\mathrm{pH}$ 7.5) containing 1 mM-EDTA, $1 \mathrm{mM}-\beta$-mercaptoethanol and $0.5 \%$ Triton X-100. After sequential centrifugations at $10000 \mathrm{~g}$ for $15 \mathrm{~min}$ and $100000 \mathrm{~g}$ for $1 \mathrm{~h}\left(4^{\circ} \mathrm{C}\right)$, the final supernatant fraction was collected as the enzyme source. An appropriate amount of enzyme solution was incubated with $1 \mathrm{ml}$ of substrate solution (100 mM-triethanolamine-HCl buffer $(\mathrm{pH}$ 7.5) containing 2.5 mM-EDTA， $0.12 \mathrm{~mm}$-NADH， $0.2 \mathrm{~mm}$-dihydroxyacetone phosphate and $0.1 \mathrm{mM}-\beta$-mercaptoethanol) and the decrease in the absorbance at $340 \mathrm{~nm}$ recorded over time (Hitachi U2001; Tokyo, Japan), and the enzyme activity expressed as nmol NADH consumed/min per mg protein.

The rate of lipolysis in adipose tissue was measured by the method of Morimoto et al. ${ }^{16}$. Adipose tissue $(0.5 \mathrm{~g})$ was minced and incubated in $2 \mathrm{ml}$ of $25 \mathrm{~mm}-\mathrm{N}$-tris(hydroxymethyl)methyl-2-aminoethanesulfonic acid buffer $(\mathrm{pH} 7.4)$ containing $135 \mathrm{~mm}-\mathrm{NaCl}, 5 \mathrm{mM}-\mathrm{KCl}, 1 \mathrm{mM}-\mathrm{MgCl}_{2}$ and $2.5 \%$ bovine serum albumin, with or without $1 \mu \mathrm{M}$-isoproterenol (a $\beta$-adrenol stimulator), at $37^{\circ} \mathrm{C}$ for 0,1 or $2 \mathrm{~h}$, then the glycerol released into the medium was measured using a commercial kit (Randox Laboratories, Crumlin, Co. Antrim, UK).

\section{Oral glucose tolerance test}

In experiment 1 , an oral glucose tolerance test was performed on rats fed the experimental diets for 6 weeks. On the test days, after overnight food deprivation, blood was collected from the tail before $(0 \mathrm{~min})$, and at 30,60, 90 and $120 \mathrm{~min}$ after, oral administration with a 2.5 M-glucose solution $(1.5 \mathrm{~g} / \mathrm{kg}$ body weight) and glucose measured as described below, then the area under the curve for serum glucose over the $2 \mathrm{~h}$ was calculated.

\section{Serum measurements}

Fasting serum obtained by tail bleeding was used for glucose and insulin measurements using, respectively, a glucose oxidase colorimetric assay (Randox Laboratories, Crumlin, UK) or an ELISA kit (Mercodia, Uppsala, Sweden). Fasting blood was collected from the abdominal vena cava, and serum TAG, cholesterol and adiponectin were determined. TAG and cholesterol were measured by enzymic methods (Randox Laboratories, Crumlin, UK), while adiponectin was measured using a mouse/rat adiponectin ELISA kit (B-Bridge, Sunnyvale, CA, USA).

\section{RNA isolation and mRNA detection}

Total RNA was extracted from homogenised adipose tissue using TRIZOL reagent according to the manufacturer's instructions (Invitrogen, New York, NY, USA). The quality of the extracted RNA was confirmed by a value of 2 for the $28 \mathrm{~S}$ ribosomal RNA:18S ribosomal RNA ratio after ethidium bromide staining. In experiment 1, levels of mRNA for PPAR $\gamma$ and ADD1/SREBP-1c were measured by Northern blotting as previously described ${ }^{12}$. In experiment 2 , levels of mRNA for fatty acid synthase (FAS), acetyl-CoA carboxylase-1 (ACC-1), lipoprotein lipase (LPL), adipocyte fatty acid-binding protein (aP2), PPAR $\gamma$ and ADD1/SREBP-1c were measured by real-time PCR. Total RNA $(1 \mu \mathrm{g})$ was reverse-transcribed into first-strand cDNA using 200 units of MMLV-RT (Promega, Medison, WI, USA). PCR was performed using $50 \mathrm{ng}$ cDNA, $2 \times \mathrm{SYBR}^{\circledR}$ Green PCR Master Mix (Applied Biosystems, Foster, CA, USA) and $200 \mathrm{~nm}$ of the primer pair. The sequences of the PCR primers used are shown in Table 2. In this assay, 36B4 was used as an internal control. Amplification using forty cycles of two steps $\left(95^{\circ} \mathrm{C}\right.$ for $15 \mathrm{~s}$ and $60^{\circ} \mathrm{C}$ for $1 \mathrm{~min}$ ) was performed on an $\mathrm{ABI}$ Prism ${ }^{\circledR} 7900 \mathrm{HT}$ sequence detection system (Applied Biosystems, Foster Ciry, CA, USA). To confirm the amplification of specific transcripts, melting-curve profiles were produced at the end of each run.

\section{Statistical analysis}

Data are expressed as mean values and standard deviations for the eight (experiment 1) or six (experiment 2) rats per group. The significance of differences between groups was analysed using one-way ANOVA and Duncan's multiple-range tests. The data were transformed to log values for the statistical analysis if the variances were not homogeneous. The general linear model of the SAS package (SAS Institute Inc., Cary, NC, USA) was used for both statistical analyses, and differences were considered significant at $P<0.05$.

\section{Results}

\section{Experiment 1}

Body weight, feed intake and adipose tissue weight. Fig. 1 shows the growth curve for the rats over the entire study 
Table 2. Sequences of the polymerase chain reaction primers and GenBank accession numbers

\begin{tabular}{|c|c|c|}
\hline Gene & Accession number & Sequence \\
\hline PPAR & AB019561 & $\begin{array}{l}\text { F: } 5^{\prime} \text {-AAACTCTGGGAGATTCTCCTGTTG-3' } \\
\text { R: } 5^{\prime} \text {-GTGCTCATAGGCAGTGCATCA-3' }\end{array}$ \\
\hline$A D D 1 / S R E B P-1 C$ & AF286470 & $\begin{array}{l}\text { F: } 5^{\prime} \text {-GGCCTGCTTGGCTCTTCTC- } 3^{\prime} \\
\text { R: } 5^{\prime} \text {-GCCAGCCACAGCTGTTGAG- } 3^{\prime}\end{array}$ \\
\hline FAS & M84761 & $\begin{array}{l}\text { F: } 5^{\prime} \text {-GCGGCTTCTGTGCCTGTTG- } 3^{\prime} \\
\text { R: } 5^{\prime} \text {-TCGGCAGCCCAGGCTAAGG-3 } 3^{\prime}\end{array}$ \\
\hline$A C C-1$ & J03808 & $\begin{array}{l}\text { F: 5'-ACCGGCTGAGTGATGGTGG-3' } \\
\text { R: 5'-GGGAGCGCATTACAGACGG-3' }\end{array}$ \\
\hline$L P L$ & L03294 & $\begin{array}{l}\text { F: 5'-CTCGCTCTCAGATGCCCTAC- } 3^{\prime} \\
\text { R: 5'-CCGGCAGGGTGAAGGGAATG-3' }\end{array}$ \\
\hline$a P 2$ & U75581 & $\begin{array}{l}\text { F: 5'-GGGACCTGGAAACTCGTCTC-3' } \\
\text { R: 5'-CTGACCGGATGACGACCAAG-3' }\end{array}$ \\
\hline $36 B 4$ & Z29530 & $\begin{array}{l}\text { F: } 5^{\prime} \text {-ATGCCCAGGGAAGACAGG-3' } \\
\text { R: } 5^{\prime} \text {-TCTGCTGCATCTGCTTGGAG-3' }\end{array}$ \\
\hline
\end{tabular}

F, forward; R, reverse; $A D D 1 / S R E B P-1 C$, adipocyte determination and differentiation factor $1 /$ sterol regulatory element-binding protein-1c; FAS, fatty acid synthase; $A C C-1$, acetyl-CoA carboxylase-1; $L P L$, lipoprotein lipase; $a P 2$, adipocyte fatty acid-binding protein; 36B4, acidic ribosomal phosphoprotein P0.

period (weeks -3 to 9). From week 3 till the end of the study, the HFT group had a significantly higher body weight than the LF group $(P<0.05)$, while the HFB and HF groups had intermediate values. Table 3 shows the body-weight gain, feed intake, feed efficiency and adipose tissue weight of the four groups of rats. There was no difference in body-weight gain between the three high-fat diet-fed groups. Among the three groups, feed intake was significantly higher in the TZD-treated group (HFT), but not changed in the HFB group, indicating the bitter taste of BM did not affect food intake. The weights of the retroperitoneal and epididymal fat pads in the HF and HFT groups were significantly higher than those in the LF and HFB groups $(P<0 \cdot 05)$. The inguinal fat pad weight was significantly higher in the HFT group than in the remaining three groups $(P<0 \cdot 01)$.

Oral glucose tolerance test and serum biochemical index. In experiment 1 , an oral glucose tolerance test was performed at week 6 . The area under the curve for serum glucose over the

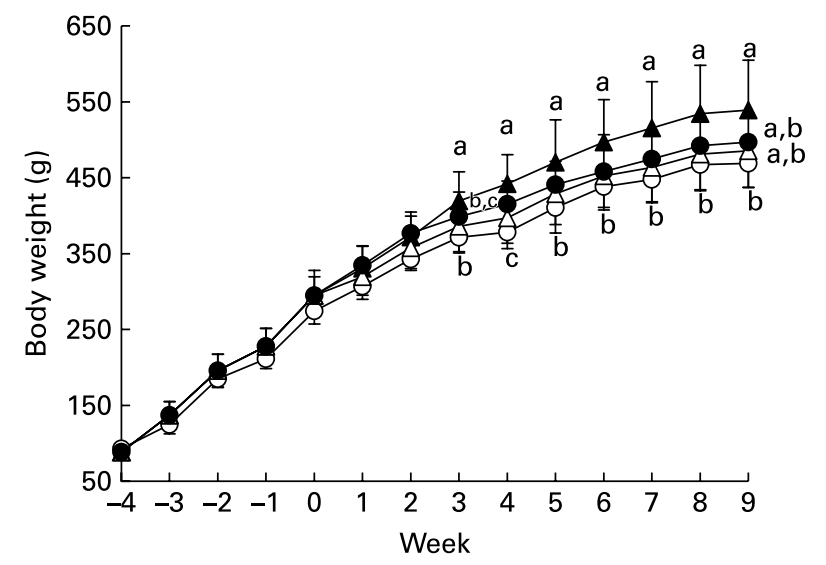

Fig. 1. Growth curves for rats fed the low-fat control diet (O), high-fat control diet $(\bullet)$, high-fat diet containing bitter melon (Momordica charantia) powder $(\Delta)$ or high-fat diet containing pioglitazone $(\boldsymbol{\Delta})$ (experiment 1). The three time periods are induction (weeks -3 to -1 ), adaptation (week 0 ) and treatment (weeks 1-9). Values are means, with their standard deviations represented by vertical bars. The significance of differences between the groups was analysed by one-way ANOVA and Duncan's multiple-range test. ${ }^{a, b, c}$ Values with unlike letters were significantly different $(P<0.05)$.
$2 \mathrm{~h}$ after an oral glucose dose was significantly increased by the HF diet (HF $v$. LF; $P<0 \cdot 05$ ). However, when BM or TZD was incorporated in the HF diet, the area under the curve for serum glucose was significantly lowered to a level comparable with that in the LF group (Table 4).

Fasting serum glucose and insulin levels were monitored at weeks $0,3,6$ and 9. There was no difference in serum glucose level between the groups at basal (data not shown), and after dietary treatment for 3, 6 and 9 weeks (Table 4). However, hyperinsulinaemia was observed in the HF group from week 3 till the end of the study (HF $v$. LF; $P<0.05$ ), but not in the DIO rats receiving BM or TZD. Table 4 also shows the serum adiponectin, TAG and cholesterol levels at the end of the study. Serum lipids did not differ between the four groups. Adiponectin levels in the HFT group were significantly higher than those in the LF group, but there was no significant difference between the three high-fat diet-fed groups.

Adipocyte size and triacylglycerol content. Figs. 2 (A) and (B) show the size distribution of adipocytes isolated from the retroperitoneal and epididymal fat pads of the rats in experiment 1 . In the two fat depots, the HF diet resulted in a significantly higher number of large adipocytes $(>180 \mu \mathrm{m})$ as compared with the LF group $(P<0 \cdot 05)$. When TZD was incorporated in the HF diet, a marked reduction in the number of large cells $(>180 \mu \mathrm{m})$ in retroperitoneal fat was observed. Compared with the HF group, the number of cells with a diameter $>180 \mu \mathrm{m}$ was significantly lower in the HFB group $(P<0.05)$ in both retroperitoneal and epididymal fat pads. In addition, the number of small cells $(20-60 \mu \mathrm{m})$ in retroperitoneal fat was significantly higher in the HFB group than in the HF group $(P<0 \cdot 05)$. As shown in Fig. $2(\mathrm{C})$, TAG content of the adipose tissues in the HFB group was comparable with that in the LF group, but was significantly lower than that in the retroperitoneal fat in the HFT group $(P<0.005)$ and that in the epididymal fat in the HF group $(P<0 \cdot 01)$. These results show that BM inhibits adipocyte hypertrophy in DIO rats.

Adipocyte lipid metabolism. The rates of lipogenesis and lipolysis in adipose tissue were measured in experiment 1. G3PDH is a lipogenic enzyme in adipose tissue responsible for directing the glycolytic intermediates into TAG synthesis. Fig. 3 (A) shows the G3PDH activity in the retroperitoneal 
Table 3. Body-weight gain, feed and energy intake, feed efficiency and adipose tissue weight of rats fed the low-fat control diet (LF), high-fat control diet (HF), high-fat diet containing bitter melon (Momordica charantia) powder (HFB) or high-fat diet containing pioglitazone (HFT) (experiment 1)*

(Mean values and standard deviations for eight rats per group)

\begin{tabular}{|c|c|c|c|c|c|c|c|c|}
\hline & \multicolumn{2}{|c|}{ LF } & \multicolumn{2}{|c|}{$\mathrm{HF}$} & \multicolumn{2}{|c|}{ HFB } & \multicolumn{2}{|c|}{$\mathrm{HFT}$} \\
\hline & Mean & SD & Mean & SD & Mean & SD & Mean & SD \\
\hline Body-weight gain (g/d) & $3.09^{\mathrm{b}}$ & 0.34 & $3 \cdot 21^{a, b}$ & 0.33 & $3 \cdot 27^{\mathrm{a}, \mathrm{b}}$ & 0.47 & $3.91^{\mathrm{a}}$ & 0.62 \\
\hline Feed intake $(\mathrm{g} / \mathrm{d})$ & $22 \cdot 5^{\mathrm{a}}$ & 1.3 & $20 \cdot 0^{\mathrm{b}}$ & 1.3 & $20 \cdot 0^{\mathrm{b}}$ & $2 \cdot 0$ & $22 \cdot 1^{\mathrm{a}}$ & $2 \cdot 0$ \\
\hline Energy intake (MJ/d) & $0.362^{\mathrm{c}}$ & 0.021 & $0.413^{\mathrm{b}}$ & 0.027 & $0.402^{b, c}$ & 0.042 & $0.463^{\mathrm{a}}$ & 0.042 \\
\hline Feed efficiency ( $\mathrm{g}$ body weight/g feed) & $0 \cdot 14^{\mathrm{b}}$ & 0.01 & $0 \cdot 16^{\mathrm{a}}$ & 0.01 & $0 \cdot 17^{\mathrm{a}}$ & 0.01 & $0 \cdot 18^{\mathrm{a}}$ & 0.02 \\
\hline \multicolumn{9}{|l|}{ Adipose tissue weight (q) } \\
\hline Epididymal fat & $8 \cdot 0^{\mathrm{b}}$ & 0.9 & $15 \cdot 0^{\mathrm{a}}$ & 3.2 & $11 \cdot 0^{\mathrm{b}}$ & 1.8 & $16 \cdot 6^{\mathrm{a}}$ & 3.4 \\
\hline Retroperitoneal fat & $10 \cdot 4^{\mathrm{b}}$ & 1.7 & $19 \cdot 4^{\mathrm{a}}$ & 3.0 & $13 \cdot 9^{b}$ & $2 \cdot 6$ & $20 \cdot 5^{\mathrm{a}}$ & 4.0 \\
\hline Inguinal fat & $0.93^{\mathrm{b}}$ & 0.22 & $1.29^{\mathrm{b}}$ & 0.38 & $1 \cdot 20^{\mathrm{b}}$ & 0.32 & $1.93^{\mathrm{a}}$ & 0.63 \\
\hline
\end{tabular}

a,b,c Mean values within a row with unlike superscript letters were significantly different $(P<0.05)$

* The significance of differences between the four groups was analysed by one-way ANOVA and Duncan's multiple-range test.

and epididymal fat of the four groups and the result almost paralleled data of their TAG content (see Fig. 2 (C)). In both fat depots, the HFT group had the highest G3PDH activity, which was significantly higher than that in the HFB and LF group $(P<0 \cdot 05)$, but was comparable with that in the HF group. Basal and stimulated lipolysis was also determined. The lipolysis rate on stimulation with $10 \mu \mathrm{M}$-isoproterenol is shown in Figs. 3 (B) and (C). Again, the HFT group had the highest value for the stimulated rate, while that in the HFB group did not differ from those in the HFT or HF group. The difference in basal lipolysis rate between the four groups was similar to that in the stimulated rate (data not shown).

Peroxisome proliferator-activated receptor- $\gamma$ and adipocyte determination and differentiation factor $1 /$ sterol regulatory element-binding protein-1c mRNA levels. The differentiation of adipocytes is delicately controlled by a transcriptional cascade. To evaluate the effect of BM on adipogenesis, the mRNA levels of mature adipocyte markers, PPAR $\gamma$ and
ADD1/SREBP-1c, were measured in experiment 1 . There was no significant difference of the PPAR $\gamma$ gene expression between the four groups. However, in epididymal fat, the HFT group had the highest ADD1/SREBP-1c mRNA level, which was significantly higher than those of the HFB and LF groups (Fig 4; $P<0.05$ ), but was comparable with the HF group. There was no significant difference between the HF and HFB groups. In retroperitoneal fat, a similar trend was also observed but did not reach statistical difference (data not shown).

The decreased G3PDH activity and the TAG content in adipose of BM-treated rats implied that the anti-adiposity effect of BM might be related to a suppression of lipogenesis in adipose tissue. Experiment 2 was thus carried out to examine the expressions of lipogenic genes.

\section{Experiment 2}

Body-weight gain and adipose weight. The body-weight gain and adipose tissue weight of rats in experiment 2 are shown in

Table 4. The area under the curve for glucose $\left(A \cup C_{g l u}\right)$ and serum glucose, insulin, adiponectin, triacylglycerol and cholesterol concentrations of rats fed the low-fat control diet (LF), high-fat control diet (HF), high-fat diet containing bitter melon (Momordica charantia) powder (HFB) or high-fat diet containing pioglitazone (HFT) (experiment 1)*

(Mean values and standard deviations for eight rats per group)

\begin{tabular}{|c|c|c|c|c|c|c|c|c|}
\hline & \multicolumn{2}{|c|}{ LF } & \multicolumn{2}{|c|}{ HF } & \multicolumn{2}{|c|}{ HFB } & \multicolumn{2}{|c|}{ HFT } \\
\hline & Mean & SD & Mean & SD & Mean & SD & Mean & SD \\
\hline \multicolumn{9}{|l|}{ Week 3} \\
\hline Glucose (pmol/l) & $6 \cdot 9$ & 0.7 & $6 \cdot 2$ & 0.9 & $6 \cdot 2$ & 0.4 & $5 \cdot 2$ & 0.7 \\
\hline Insulin (pmol/l) & $81^{\mathrm{b}}$ & 28 & $173^{a}$ & 76 & $112^{\mathrm{b}}$ & 43 & $111^{\mathrm{b}}$ & 56 \\
\hline \multicolumn{9}{|l|}{ Week 6} \\
\hline $\mathrm{AUC}_{\mathrm{glu}}(\mathrm{mmol} \times \mathrm{min} / \mathrm{l}) \dagger$ & $665^{\mathrm{b}}$ & 47 & $780^{a}$ & 151 & $638^{b}$ & 56 & $633^{b}$ & 61 \\
\hline Glucose (pmol/l) & $6 \cdot 3$ & 0.6 & $6 \cdot 5$ & 0.7 & $5 \cdot 8$ & 0.6 & $6 \cdot 3$ & 0.7 \\
\hline Insulin (pmol/l) & $78^{b}$ & 30 & $160^{\mathrm{a}}$ & 79 & $87^{\mathrm{b}}$ & 30 & $102^{a, b}$ & 51 \\
\hline \multicolumn{9}{|l|}{ Week 9} \\
\hline Glucose (pmol/l) & $5 \cdot 7$ & 0.5 & $5 \cdot 7$ & 0.4 & $5 \cdot 5$ & 0.7 & $5 \cdot 8$ & 0.6 \\
\hline Insulin (pmol/l) & $81^{\mathrm{b}}$ & 31 & $142^{a}$ & 36 & $76^{\mathrm{b}}$ & 46 & $83^{b}$ & 51 \\
\hline Adiponectin (mg/l) & $8 \cdot 3^{b}$ & $2 \cdot 6$ & $10 \cdot 4^{a, b}$ & $2 \cdot 5$ & $10 \cdot 9^{a, b}$ & $2 \cdot 1$ & $12 \cdot 1^{\mathrm{a}}$ & $3 \cdot 1$ \\
\hline TAG $(\mathrm{mmol} / \mathrm{l})$ & 0.99 & 0.27 & $1 \cdot 19$ & 0.49 & $1 \cdot 10$ & 0.27 & 0.91 & 0.31 \\
\hline Cholesterol (mmol/l) & 1.45 & 0.19 & $1 \cdot 38$ & 0.43 & $1 \cdot 25$ & 0.38 & $1 \cdot 14$ & $0 \cdot 21$ \\
\hline
\end{tabular}

a,b,c Mean values within a row with unlike superscript letters were significantly different $(P<0.05)$.

* The significance of differences between the four groups was analysed by one-way ANOVA and Duncan's multiple-range test.

† Area under the curve over the $2 \mathrm{~h}$ during an oral glucose tolerance test. 
(A)

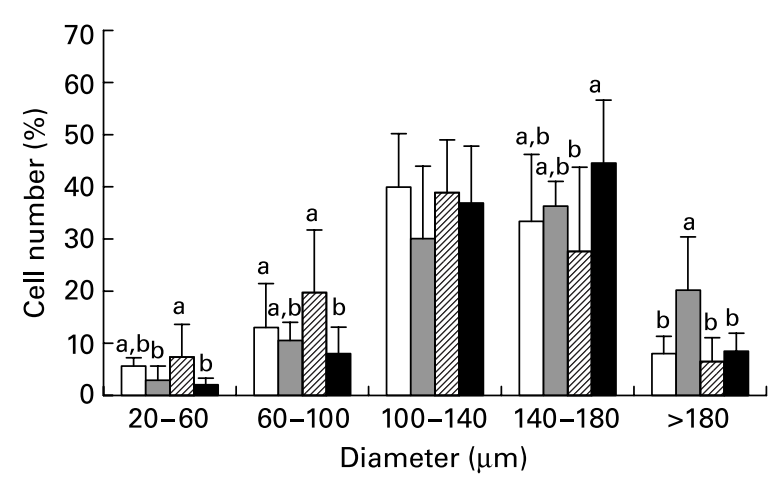

(B)

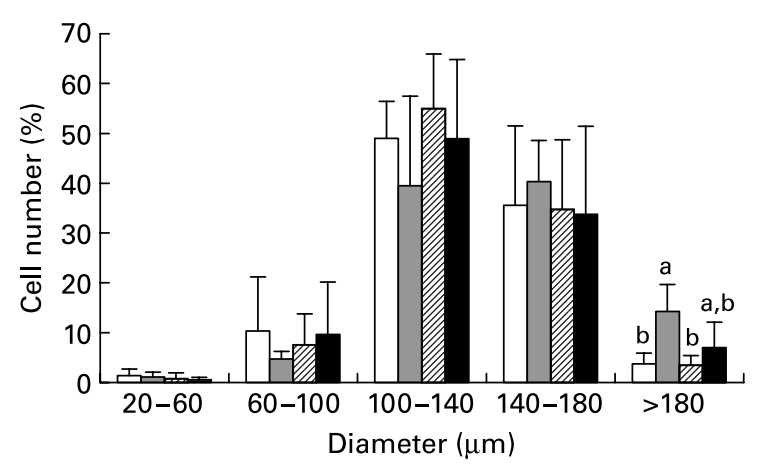

(C)

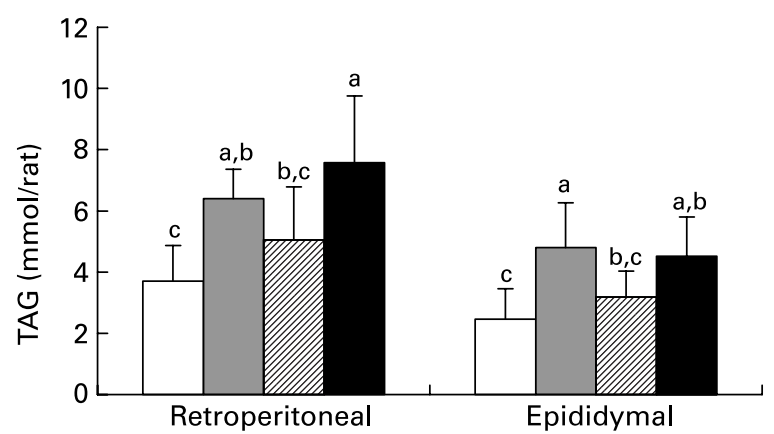

Fig. 2. Diameter distribution curves of adipocytes in the retroperitoneal $(A)$ and epididymal $(B)$ fat and TAG content $(C)$ in the retroperitoneal and epididymal fat of rats fed the low-fat control diet $(\square)$, high-fat control diet $(\square)$, high-fat diet containing bitter melon (Momordica charantia) powder (四) or high-fat diet containing pioglitazone ( $\square$ ) (experiment 1). Values are means, with their standard deviations represented by vertical bars. The significance of differences between the groups was analysed by one-way ANOVA and Duncan's multiple-range test. ${ }^{a, b, c}$ Values with unlike letters were significantly different $(P<0.05)$

Table 5. Again, no difference in body-weight gain between the LF, HF and HFB groups was seen. However, the weight of the retroperitoneal and epididymal fat in the HFB group was significantly lower than that in the HF group $(P<0.005)$ and comparable with that in the LF group, as observed in experiment 1.

Expression of lipogenic genes and their transcriptional regulators. To examine whether the anti-adiposity effect of $\mathrm{BM}$ might be related to a suppression of lipogenesis in adipose tissues, the expression of four lipogenic genes, FAS, ACC-1,
$L P L$, and $a P 2$, and their transcriptional regulators, ADD1/ SREBP-1c and PPAR $\gamma$, was compared in adipose tissues of the LF, HF and HFB groups. As shown in Table 5, the expression of all four lipogenic genes was down regulated by $\mathrm{BM}$ in the epididymal fat $(P<0 \cdot 05$; HFB $v$. HF), to a level that was about half of those in the HF group. There was no difference between the LF and HF groups, except that the FAS mRNA level tended to be lower in the LF than in the HF group. On the other hand, PPAR $\gamma$ and ADD1/ SREBP-1c mRNA levels did not differ between the three groups. Similar results were also observed in the retroperitoneal fat (data not shown).

\section{Discussion}

Following the in vitro evidence that $\mathrm{BM}$ is a dual agonist of PPAR $\alpha$ and PPAR $\gamma^{4}$, the present in vivo study confirmed that BM, just like the anti-diabetic drug TZD, ameliorated the hyperinsulinaemia and glucose intolerance induced by an $\mathrm{HF}$ diet. In contrast to the well-known adipogenic side effect of TZD, BM reduced visceral fat accretion and inhibited adipocyte hypertrophy by down regulating expression of the lipogenic genes $F A S, A C C-1, L P L$ and $a P 2$ in adipose tissue.

$\mathrm{BM}$ has been used for the treatment of diabetes throughout the world ${ }^{3,17}$. Its hypoglycaemic effect has been demonstrated in type 1 and type 2 diabetic rodents ${ }^{18,19}$ and in human subjects with type 2 diabetes mellitus ${ }^{20}$. Numerous studies have been performed to determine the functional components and the mechanism of action of its anti-diabetic function. Its hypoglycaemic effect has been attributed to protection of $\beta$-cells ${ }^{18}$, alterations in glucose metabolism ${ }^{21}$ and its insulin-like effect $^{22,23}$. It is possible that different bioactive components are involved and that the hypoglycaemic effect is produced by more than one mechanism. Using a CHO-K1 cell clone stably transfected with a (UAS) $)_{4}$-tk-alkaline phosphatase reporter and a chimeric receptor of GAL4-rPPAR $\alpha$ (or GAL4-rPPAR $\gamma$ ) ligand-binding domain, Chao \& Huang ${ }^{4}$ found that wild BM contains PPAR $\alpha$ and PPAR $\gamma$ activator(s) that can be extracted by non-polar organic solvents. This provides another explanation for the well-known hypoglycaemic, hypolipidaemic and anti-inflammatory effects and the possible anti-adiposity effect of BM.

The anti-adiposity effect of BM was first reported by Chen et $a .^{7}$, who subsequently showed a general decrease in the TAG content of the liver and muscle in rats fed an HF diet containing freeze-dried BM juice ${ }^{8}$. In the present study, we focused on cell size and lipid metabolism in the adipose tissues of BM-fed rats, and compared these results with those obtained using TZD, a well-known insulin-sensitising agent that also increases adipogenesis at the cellular level by activation of PPAR $\gamma^{11}$. To exclude the possible contribution of a decreased food or energy intake, the feeding experiment in the present study was started with an adaptation period (week 0) so that rats of the BM group got used to the bitter taste. In addition, the lyophilised BM powder was incorporated into the HF diet by substituting it for the equivalent amount of protein, fat, ash and fibre. These two strategies have successfully kept the feed and energy intake of the HFB group comparable with that of the HF group (Table 3).

The higher energy intake in the TZD-treated rats observed in the present study agrees with previous reports, and was 

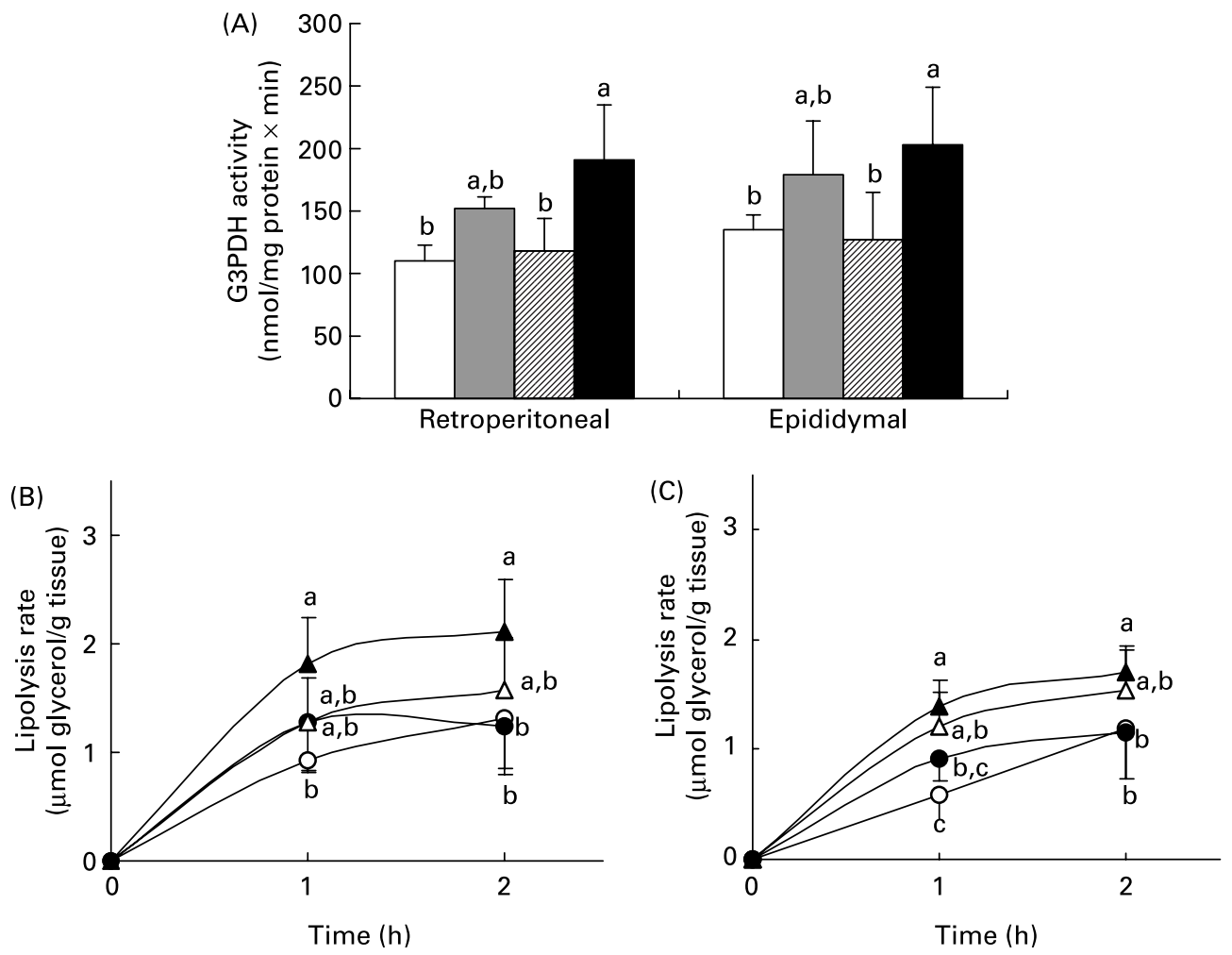

Fig. 3. Glycerol-3-phosphate dehydrogenase (G3PDH) activity (A) and lipolysis rate after stimulation with $10 \mu \mathrm{M}$-isoproterenol in the retroperitoneal (B) and epididymal (C) fat of rats fed the low-fat control diet $(\square, \bigcirc)$, high-fat control diet $(\square, \bullet)$, high-fat diet containing bitter melon (Momordica charantia) powder $(\mathbb{Q}, \Delta)$ or high-fat diet containing pioglitazone $(\mathbf{\square}, \mathbf{\Lambda})$ (experiment 1). Values are means, with their standard deviations represented by vertical bars. The significance of differences between the groups was analysed by one-way ANOVA and Duncan's multiple range test. ${ }^{\mathrm{a}, \mathrm{b}, \mathrm{c}}$ Values with unlike letters were significantly different $(P<0 \cdot 05)$.

attributed to lower leptin expression in adipose tissue ${ }^{24,25}$. Although the increased energy intake and adipogenic action of TZD favour energy storage in adipocytes, only subcutaneous fat (for example, inguinal fat), but not visceral fat (for example, retroperitoneal and epididymal fat), was increased in the HFT group as compared with the HF group. In the two visceral fat depots examined, the number of adipocytes with a diameter $>180 \mu \mathrm{m}$ was lower in the TZD-treated group than in the HF group. Okuno et al. ${ }^{26}$ treated lean and obese ( $f a / f a$ ) Zucker rats with troglitazone (a TZD) for $19 \mathrm{~d}$ and found that it caused an increase in the number of small adipocytes, decrease in the number of enlarged adipocytes and concomitantly normalised TNF- $\alpha$ and leptin expression, partially providing an explanation for the discrepancy that TZD relieves insulin resistance, but induces adipogenesis. In the present study, the TZD-treated group showed the highest G3PDH activity and also the highest basal and stimulated lipolysis in adipose tissue. This is in accordance with Bogacka et $a .^{27}$, who reported that lipid storage genes, including those for $G 3 P D H, L P L$ and $F A S$, are up regulated in the subcutaneous fat of pioglitazone-treated diabetic patients. A major lipolysis enzyme in adipose tissue, hormone-sensitive lipase, has been found to be up regulated by PPAR $\gamma$ agonists (rosiglitazone and pioglitazone) in differentiating preadipocytes ${ }^{28}$.

When compared with the HF group, BM reduced fat pad weight, cell size and TAG content in the visceral fat of DIO rats. In human subjects, insulin resistance is strongly correlated with visceral fat accumulation. Interventions that reduce visceral adiposity could potentially improve insulin sensitivity. Recently, adipose tissue has been recognised to serve not only as an energy storage, but also as an endocrine organ by releasing adipocytokines (for example, TNF- $\alpha$, leptin, adiponectin, resistin and NEFA) into the circulation to regulate both adipose tissue mass and the functions of other tissues by affecting systemic lipid and glucose metab-

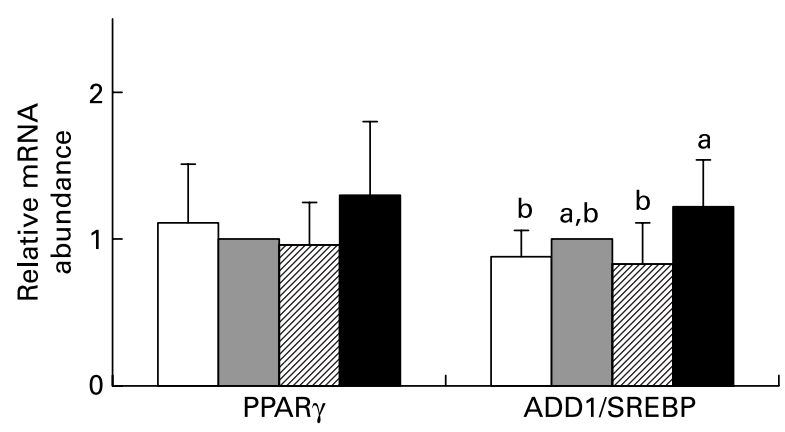

Fig. 4. PPAR $\gamma$ and adipocyte determination and differentiation factor $1 /$ sterol regulatory element-binding protein-1c (ADD1/SREBP) mRNA levels in the epididymal fat of rats fed the low-fat control diet ( $\square$ ), high-fat control diet ( $\square$;

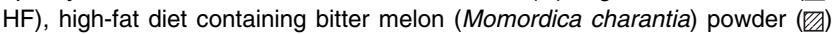
or high-fat diet containing pioglitazone ( $\square$ ) (experiment 1). The Northern blotting results were quantified by image analysis. Each value was normalised to that for $18 \mathrm{~S}$ ribosomal RNA, then the relative mRNA abundance was calculated by taking the normalised value for the HF group as 1. Values are means, with their standard deviations represented by vertical bars. The significance of differences between the groups was analysed by one-way ANOVA and Duncan's multiple range test. ${ }^{a, b}$ Values with unlike letters were significantly different $(P<0.05)$. 
Table 5. Body-weight gain, adipose tissue weight and gene expression in the epididymal fat of rats fed the low-fat control diet (LF), high-fat control diet (HF) or high-fat diet containing bitter melon (Momordica charantia) powder (HFB) (experiment 2)* (Mean values and standard deviations for six rats per group)

\begin{tabular}{|c|c|c|c|c|c|c|}
\hline & \multicolumn{2}{|c|}{ LF } & \multicolumn{2}{|c|}{ HF } & \multicolumn{2}{|c|}{ HFB } \\
\hline & Mean & $\mathrm{SD}$ & Mean & SD & Mean & SD \\
\hline Body-weight gain (g/d) & $3 \cdot 0$ & $1 \cdot 3$ & 3.2 & 0.6 & $3 \cdot 2$ & 0.3 \\
\hline \multicolumn{7}{|l|}{ Adipose tissue weight (g) } \\
\hline Epididymal fat & $11 \cdot 3^{b}$ & $4 \cdot 7$ & $16 \cdot 1^{a}$ & 4.5 & $13 \cdot 4^{b}$ & $6 \cdot 0$ \\
\hline Retroperitoneal fat & $10 \cdot 9^{b}$ & $1 \cdot 2$ & $18 \cdot 3^{a}$ & $5 \cdot 6$ & $14 \cdot 3^{b}$ & $6 \cdot 7$ \\
\hline Inguinal fat & 0.50 & 0.11 & 0.60 & 0.15 & 0.45 & 0.20 \\
\hline \multicolumn{7}{|l|}{ mRNA level (\%)† } \\
\hline PPAR $\gamma$ & 1.08 & 0.41 & 1.00 & 0.30 & 1.02 & 0.28 \\
\hline ADD1/SREBP-1C & 1.07 & 0.70 & 1.00 & 0.22 & 0.88 & 0.32 \\
\hline FAS & $0.74^{a, b}$ & 0.47 & $1.00^{a}$ & 0.70 & $0.37^{\mathrm{b}}$ & 0.12 \\
\hline ACC-1 & $1.07^{\mathrm{a}}$ & 0.44 & $1.00^{a}$ & 0.60 & $0.51^{\mathrm{b}}$ & 0.22 \\
\hline LPL & $0.99^{a}$ & 0.04 & $1.00^{a}$ & 0.20 & $0.45^{b}$ & 0.14 \\
\hline aP2 & $1.00^{a}$ & 0.17 & $1.00^{\mathrm{a}}$ & 0.20 & $0.68^{b}$ & 0.18 \\
\hline
\end{tabular}

$A D D 1 / S R E B P-1 C$, adipocyte determination and differentiation factor $1 /$ sterol regulatory element-binding protein-1c; $F A S$, fatty acid synthase; $A C C$-1, acetyl-CoA carboxylase-1; $L P L$, lipoprotein lipase; $a P 2$, adipocyte fatty acid-binding protein

${ }^{a, b, c}$ Mean values within a row with unlike superscript letters were significantly different $(P<0.05)$.

* The significance of differences between the three groups was analysed by one-way ANOVA and Duncan's multiple-range test.

†The mRNA level is expressed as a fraction of that in the HF group assigned a value of 1 .

olism $^{29}$. The decrease in the number of large adipocytes is proposed to be an important mechanism for improving insulin sensitivity by reducing secretion of TNF- $\alpha$, leptin and NEFA from enlarged fat cells, which are known to interfere with insulin signalling in several ways ${ }^{10,26,30,31}$. In addition, small adipocytes take up and oxidise more glucose than large adipocytes in the presence of insulin ${ }^{32}$.

The inhibition of adipocyte hypertrophy by long-term consumption of BM may be mediated by increased lipolysis, fatty acid oxidation and/or decreased lipogenesis in adipose tissue. The former has been demonstrated by Chen $\& \mathrm{Li}^{8}$, who reported higher circulation levels of catecholamines and NEFA in BM-treated rats. In the present study, although the lipolysis rate was not increased in the ex vivo adipose tissue from the HFB group (Figs. 3 (B) and (C)), we cannot eliminate the possibility of increased sympathetic activity in vivo, since we did not measure blood hormone concentrations. However, in the present study, serum NEFA levels were not increased by BM administration (data not shown).

Increased expression of PPAR $\alpha$ target genes (i.e. coding for an enzyme or protein involved in fatty acid oxidation and transport) has been observed in the H4IIEC3 murine hepatoma cell line treated with a BM extract ${ }^{4}$. A lower liver and muscle TAG content, accompanied by increased activity of enzymes involved in fatty acid $\beta$ oxidation, was also observed by Chan et al. ${ }^{9}$. Results of the present study further demonstrated a reduction in lipogenesis in the adipose tissues of BM-treated rats. This evidence included a slightly lowered G3PDH activity, and a significant reduction in lipogenic gene expression in adipose.

Although the mRNA levels of lipogenic genes including $F A S, A C C-1, L P L$ and $a P 2$ were significantly lower in the adipose tissue of the HFB group than in the HF and LF groups, $P P A R \gamma$ and SREBP-1c, the two transcriptional factors controlling their expression, were not different at the mRNA level.
The transcriptional activity of PPAR is mainly regulated by the presence of its ligand and may be further regulated by protein phosphorylation and dephosphrylation ${ }^{33}$, while that of ADD1/SREBP-1c is known to be regulated by proteolytic cleavage of ADD1/SREBP-1c precursor and the subsequent translocation of the released active form into the nucleus ${ }^{34}$. Thus, the transcriptional activity of PPAR and ADD1/ SREBP-1c might not be revealed by their own mRNA levels.

Despite that the BM extract has been shown to activate PPAR $y$ in a transactivation assay ${ }^{4}$, the mRNA level of its target genes, i.e. $L P L$ and $a P 2$, was not increased, but decreased in the adipose tissue. This unexpected result might partly be explained by the fact that there are multiple regulatory sites in the promoter region of the $L P L$ and $a P 2$ genes, indicating that these genes are under multiple regulation $^{35,36}$, in addition to PPAR $\gamma$. Besides, the potency of PPAR ligands existing in natural foods or herb materials is usually much lower than that of synthetic drugs. This can be seen from the much higher $50 \%$ effective concentration $\left(\mathrm{EC}_{50}\right)$ in the transactivation assay and the lower affinity in the ligand-binding assay. Furthermore, the co-activators and co-repressors expressed in liver and adipose tissue in rodents might be different from that of $\mathrm{CHO}$ cells used in the transactivation assay. In addition, the lack of concordance between the results of the transactivation assay and the in vivo study could partly be due to a metabolic or hormonal effect which does not exist in the in vitro study. For example, fish oil has been shown to be a PPAR $\alpha$ and PPAR $\gamma$ activator, but the expression of $L P L$ and PEPCK genes in adipose was down regulated, rather than up regulated, when tested in vivo ${ }^{37}$.

Based on the observed suppression of FAS and ACC-1 gene expression, a speculation that BM might antagonise the transcriptional activity of ADD1/SREBP-1c was raised. However, Nerurkar et al $^{38}$ reported that nuclear SREBP-1c is increased in BM juice-treated HepG2 cells, although TAG is lowered. 
In the present study, the mRNA level of SREBP-1c in adipose was not changed by BM administration. The role of SREBP$1 \mathrm{c}$ in the regulation of lipogenic enzyme gene expression is well established in hepatocytes, but whether a similar role also exists in adipose is not clear, given that its importance in adipocyte differentiation has been characterised ${ }^{39}$. Results of several reports have indicated that mRNA levels of SREBP-1c do not coincide with the changes in adipose lipogenic gene expression ${ }^{40,41}$. Recently, Sekiya et al. $^{42}$ reported that adipocyte lipogenesis is independent of control by SREBP-1c. Using the chromatin immunoprecipitation assay, they showed that the mature SREBP-1c failed to bind to the functional cis-element of FAS promoter in adipocytes, but could bind in hepatocytes. Recently, a role for liver X receptor in de novo lipogenesis and lipid accumulation in adipocytes has been proposed, but the evidence is still controversial ${ }^{43-45}$. Therefore, the transcription factors that mediate the lipogenic gene expression in adipocytes through which BM exerts its anti-adiposity effect remain unclear and merit further study. On the other hand, the possibility that the lowered lipogenic gene expression in BM-supplemented rats was a direct effect of a lowered serum insulin level could not be excluded.

In spite of its bitter taste, which is unacceptable to some individuals, BM is a very common vegetable and has been consumed in Oriental societies for hundreds of years. The Chinese traditional conception is that diet cures more than the doctor. The present study shows that BM could ameliorate insulin resistance as effectively as the anti-diabetic drug TZD. Furthermore, BM could inhibit adipocyte hypertrophy by down regulating lipogenic gene expression in visceral fat, avoiding the adipogenic side effect of TZD. The potential of BM as part of the daily diet or as a supplement for ameliorating the metabolic syndrome is worth further exploration.

In conclusion, supplementation of BM to an HF diet significantly decreased the number of large adipocytes $(>180 \mu \mathrm{m})$, increased the number of small adipocytes (20-60 $\mu \mathrm{m})$ and down regulated the expression of lipogenic genes in adipose tissues of rats. It also ameliorated the glucose intolerance and hyperinsulinaemia in HF diet-fed rats.

\section{Acknowledgements}

The present study was supported by grants from the National Science Council (NSC93-2317B-039-004), Taipei, Taiwan. We thank the Takeda Pharmaceutical Company Ltd (Osaka, Japan) for kindly supplying pioglitazone (AD-4833).

\section{References}

1. Plutzky J (2000) Emerging concepts in metabolic abnormalities associated with coronary artery disease. Curr Opin Cardiol 15, $416-421$.

2. Grover JK \& Yadav SP (2004) Pharmacological actions and potential uses of Momordica charantia: a review. J Ethnopharmacol 93, 123-132.

3. Krawinkel MB \& Keding GB (2006) Bitter gourd (Momordica charantia): a dietary approach to hyperglycemia. Nutr Rev 64, $331-337$

4. Chao CY \& Huang CJ (2003) Bitter gourd (Momordica charantia) extract activates peroxisome proliferator-activated receptors and upregulates the expression of the acyl CoA oxidase gene in H4IIEC3 hepatoma cells. J Biomed Sci 10, 782-791.

5. Desvergne B \& Wahli W (1999) Peroxisome proliferator-activated receptors: nuclear control of metabolism. Endocr Rev 20, 649-688.

6. Berger JP, Akiyama TE \& Meinke PT (2005) PPARs: therapeutic targets for metabolic disease. Trends Pharmacol Sci 26, 244-251.

7. Chen Q, Chan LL \& Li ET (2003) Bitter melon (Momordica charantia) reduces adiposity, lowers serum insulin and normalizes glucose tolerance in rats fed a high fat diet. $J$ Nutr 133, 1088-1093.

8. Chen Q \& Li ET (2005) Reduced adiposity in bitter melon (Momordica charantia) fed rats is associated with lower tissue triglyceride and higher plasma catecholamines. Br J Nutr 93, 747-754.

9. Chan LL, Chen Q, Go AG, Lam EK \& Li ET (2005) Reduced adiposity in bitter melon (Momordica charantia)fed rats is associated with increased lipid oxidative enzyme activities and uncoupling protein expression. J Nutr 135, $2517-2523$.

10. Arner $P(2005)$ Insulin resistance in type 2 diabetes - role of the adipokines. Curr Mol Med 5, 333-339.

11. Lambe KG \& Tugwood JD (1996) A human peroxisome-proliferator-activated receptor- $\gamma$ is activated by inducers of adipogenesis, including thiazolidinedione drugs. Eur J Biochem 239, $1-7$.

12. Hsu SC \& Huang CJ (2006) Reduced fat mass in rats fed a high oleic acid-rich safflower oil diet is associated with changes in expression of hepatic PPAR(and adipose SREBP-1c-regulated genes. J Nutr 136, 1779-1785.

13. Hirsch J \& Gallian E (1968) Methods for the determination of adipose cell size in man and animals. J Lipid Res 9, 110-119.

14. Folch J, Lees M \& Sloane Stanley GH (1957) A simple method for the isolation and purification of total lipides from animal tissues. J Biol Chem 226, 497-509.

15. Kozak LP \& Jensen JT (1974) Genetic and developmental control of multiple forms of 1-glycerol 3-phosphate dehydrogenase. J Biol Chem 249, 7775-7781.

16. Morimoto C, Kameda K, Tsujita T \& Okuda H (2001) Relationships between lipolysis induced by various lipolytic agents and hormone-sensitive lipase in rat fat cells. J Lipid Res 42, 120-127.

17. Yeh GY, Eisenberg DM, Kaptchuk TJ \& Phillips RS (2003) Systematic review of herbs and dietary supplements for glycemic control in diabetes. Diabetes Care 26, 1277-1294.

18. Ahmed I, Adeghate E, Sharma AK, Pallot DJ \& Singh J (1998) Effects of Momordica charantia fruit juice on islet morphology in the pancreas of the streptozotocin-diabetic rat. Diabetes Res Clin Pract 40, 145-151.

19. Miura T, Itoh C, Iwamoto N, et al. (2001) Hypoglycemic activity of the fruit of the Momordica charantia in type 2 diabetic mice. J Nutr Sci Vitaminol 47, 340-344.

20. Akhtar MS (1982) Trial of Momordica charantia Linn (Karela) powder in patients with maturity-onset diabetes. J Pak Med Assoc 32, 106-107.

21. Shibib BA, Khan LA \& Rahman R (1993) Hypoglycaemic activity of Coccinia indica and Momordica charantia in diabetic rats: depression of the hepatic gluconeogenic enzymes glucose6-phosphatase and fructose-1,6-bisphosphatase and elevation of both liver and red-cell shunt enzyme glucose-6-phosphate dehydrogenase. Biochem J 292, 267-270.

22. Ng TB, Wong CM, Li WW \& Yeung HW (1986) Insulin-like molecules in Momordica charantia seeds. J Ethnopharmacol 15, 107-117.

23. Cummings E, Hundal HS, Wackerhage H, Hope M, Belle M, Adeghate E \& Singh J (2004) Momordica charantia fruit juice stimulates glucose and amino acid uptakes in L6 myotubes. Mol Cell Biochem 261, 99-104. 
24. De Vos P, Lefebvre AM, Miller SG, Guerre-Millo M, Wong K, Saladin R, Hamann LG, Staels B, Briggs MR \& Auwerx J (1996) Thiazolidinediones repress $o b$ gene expression in rodents via activation of peroxisome proliferator-activated receptor $\gamma$. $J$ Clin Invest 98, 1004-1009.

25. Zhang B, Graziano MP, Doebber TW, et al. (1996) Down-regulation of the expression of the obese gene by an antidiabetic thiazolidinedione in Zucker diabetic fatty rats and $d b / d b$ mice. J Biol Chem 271, 9455-9459.

26. Okuno A, Tamemoto H, Tobe K, et al. (1998) Troglitazone increases the number of small adipocytes without the change of white adipose tissue mass in obese Zucker rats. J Clin Invest 101, 1354-1361.

27. Bogacka I, Xie H, Bray GA \& Smith SR (2004) The effect of pioglitazone on peroxisome proliferator-activated receptor- $\gamma$ target genes related to lipid storage in vivo. Diabetes Care 27, 1660-1667.

28. Deng T, Shan S, Li PP, Shen ZF, Lu XP, Cheng Z \& Ning ZQ (2006) Peroxisome proliferator-activated receptor- $\gamma$ transcriptionally up-regulates hormone-sensitive lipase via the involvement of specificity protein-1. Endocrinology 147, 875-884.

29. Ahima RS \& Flier JS (2000) Adipose tissue as an endocrine organ. Trends Endocrinol Metab 11, 327-332.

30. Hotamisligil GS, Peraldi P, Budavari A, Ellis R, White MF \& Spiegelman BM (1996) IRS-1-mediated inhibition of insulin receptor tyrosine kinase activity in TNF- $\alpha$ - and obesity-induced insulin resistance. Science 271, 665-668.

31. Griffin ME, Marcucci MJ, Cline GW, Bell K, Barucci N, Lee D, Goodyear LJ, Kraegen EW, White MF \& Shulman GI (1999) Free fatty acid-induced insulin resistance is associated with activation of protein kinase $\mathrm{C}$ theta and alterations in the insulin signaling cascade. Diabetes 48, 1270-1274.

32. Olefsky JM (1976) The effects of spontaneous obesity on insulin binding, glucose transport, and glucose oxidation of isolated rat adipocytes. $J$ Clin Invest 57, 842-851.

33. Hu E, Kim JB, Sarraf P \& Spiegelman BM (1996) Inhibition of adipogenesis through MAP kinase-mediated phosphorylation of PPAR $\gamma$. Science 274, 2100-2103.

34. Brown MS, \& Goldstein JL (1997) The SREBP pathway: regulation of cholesterol metabolism by proteolysis of a membranebound transcription factor. Cell 89, 331-340.
35. Yang VW, Christy RJ, Cook JS, Kelly TJ \& Lane MD (1989) Mechanism of regulation of the 422(aP2) gene by cAMP during preadipocyte differentiation. Proc Natl Acad Sci U S A 86, 3629-3633.

36. Zhang Y, Repa JJ, Gauthier K \& Mangelsdorf DJ (2001) Regulation of lipoprotein lipase by the oxysterol receptors, LXR LXRß. J Biol Chem 276, 43018-43024.

37. Raclot T, Groscolas R, Langin D \& Ferre P (1997) Sitespecific regulation of gene expression by $n-3$ polyunsaturated fatty acids in rat white adipose tissues. J Lipid Res 38, 1963-1972.

38. Nerurkar PV, Pearson L, Efird JT, Adeli K, Theriault AG \& Nerurkar VR (2005) Microsomal triglyceride transfer protein gene expression and apoB secretion are inhibited by bitter melon in HepG2 cells. J Nutr 135, 702-706.

39. Kim JB \& Spiegelman BM (1996) ADD1/SREBP1 promotes adipocytes differentiation and gene expression linked to fatty acid metabolism. Genes Dev 10, 1096-1107.

40. Palmer DG, Rutter GA \& Tavare JM (2002) Insulin-stimulated fatty acid synthase gene expression does not require increased sterol response element binding protein 1 transcription in primary adipocytes. Biochem Biophys Res Commun 291, 439-443.

41. Bertile F \& Raclot T (2004) mRNA levels of SREBP-1c do not coincide with the changes in adipose lipogenic gene expression. Biochem Biophys Res Commun 325, 827-834.

42. Sekiya M, Yahagi N, Matsuzaka T, et al. (2007) Sterol regulatory element-binding protein (SREBP)-1-independent regulation of lipogenic gene expression in adipocytes. J Lipid Res (Epublication ahead of print version 24 April 2007).

43. Juvet LK, Andresen SM, Schuster GU, et al. (2003) On the role of liver X receptors in lipid accumulation in adipocytes. Mol Endocrinol 17, 172-182.

44. Darimont C, Avanti O, Zbinden I, Leone-Vautravers P, Mansourian R, Giusti V \& Mace K (2006) Liver X receptor preferentially activates de novo lipogenesis in human preadipocytes. Biochimie 88, 309-318.

45. Stulnig TM, Steffensen KR, Gao H, Reimers M, DahlmanWright K, Schuster GU \& Gustafsson J (2002) Novel roles of liver $\mathrm{X}$ receptors exposed by gene expression profiling in liver and adipose tissue. Mol Pharmacol 62, 1299-1305. 